\title{
Vitiligo y vitamina D
}

Vitiligo and vitamin $D$

\section{Andrea Castaño Villegas ${ }^{1}$, Catalina Moreno Zuluaga', Leonardo Javier Medina Albis², Óscar Jairo Valencia Ocampo ${ }^{2}$}

1. Médica, residente de Dermatología, Universidad de Antioquia, Medellín, Colombia

2. Médico dermatólogo; docente de Dermatología, Universidad de Antioquia, Medellín, Colombia. Centro de Investigaciones Dermatológicas CIDERM

\section{RESUMEN}

El vitiligo es la despigmentación cutánea adquirida más común. Se caracteriza por máculas acrómicas que afectan la autoimagen de los pacientes e impactan negativamente su calidad de vida. En cuanto a las teorías sobre la etiopatogénesis del vitiligo, está la autoinmunidad. Se ha demostrado que hay un déficit de vitamina D en numerosas enfermedades autoinmunitarias.

La vitamina D es una hormona esencial con efectos pleiotrópicos y funciones especialmente antiapoptóticas y modificadoras de la proliferación y diferenciación de los melanocitos. Hipotéticamente, puede desempeñar un papel coadyuvante en la repigmentación de las lesiones vitiliginosas. La actividad inmunorreguladora de la vitamina D podría ser utilizada en el tratamiento del vitiligo.

A continuación, se hace una revisión de tema sobre el vitiligo, su relación con las concentraciones de la vitamina D y las influencias que podría tener en la fisiopatología; además, se analiza su posible uso como herramienta terapéutica para el vitiligo. El comportamiento de los niveles de vitamina D en rangos de deficiencia e insuficiencia entre pacientes con vitiligo y controles sanos son controversiales; algunos muestran niveles más bajos en el grupo de vitiligo y otros no muestran diferencias entre los grupos. A pesar de lo anterior, los estudios recientes sugieren una relación entre la insuficiencia de vitamina $\mathrm{D}$ en pacientes con vitiligo y un riesgo mayor de padecer otras enfermedades autoinmunitarias y que el uso de dosis altas de vitamina $\mathrm{D}$ en pacientes con vitiligo podría mejorar la repigmentación. La información revisada permite concluir que la relación entre el vitiligo y los niveles de vitamina D requiere de más estudios que aclaren su papel en la inmunopatogénesis y en la probabilidad de recomendar su uso terapéutico.

PALABRAS CLAVE: vitiligo, vitamina D, melanocitos, deficiencia de vitamina $\mathrm{D}$

\section{SUMMARY}

Vitiligo is the most common acquired skin depigmentation. It is characterized by acromic macules that affect the self-image of patients and negatively impact their quality of life. Among the theories about the etiopathogenesis of vitiligo, is autoimmunity. Vitamin D deficiency has been demonstrated in numerous autoimmune diseases.
Correspondencia:

Óscar Jairo Valencia Ocampo

Email:

oscar.valencia@udea.edu.co

Recibido: 04/03/18

Aceptado: 30/07/18

Conflictos de interés:

No se reportan conflictos de interés.

Financiación:

Sección de Dermatologia. Facultad de Medicina. Universidad de Antioquia. 
Vitamin D is an essential hormone with pleiotropic effects, and especially antiapoptotic functions and modifiers of the proliferation and differentiation of melanocytes. Hypothetically, it can play a coadjuvant role in the repigmentation of vitiliginous lesions. The immunoregulatory activity of vitamin D could be used in the treatment of vitiligo.

Next, there is a review of the subject on vitiligo, its relationship with the concentrations of vitamin $\mathrm{D}$ and the influences that could have on the physiopathology. In addition, its possible use as a therapeutic tool for vitiligo is analyzed. The behavior of vitamin D levels in deficiency and insufficiency ranges between vitiligo patients and healthy controls are controversial, some show lower levels in the vitiligo group and others do not show differences between the groups. Despite the above, recent studies suggest a relationship between vitamin D insufficiency in patients with vitiligo and a higher risk of suffering from other autoimmune diseases and that the use of high doses of vitamin $\mathrm{D}$ in patients with vitiligo could improve the repigmentation. The information reviewed allows us to conclude that the relationship between vitiligo and vitamin D levels requires more studies to clarify its role in immunopathogenesis and the likelihood of recommending its therapeutic use.

KEY WORDS: Vitiligo, vitamin D, melanocytes, vitamin D deficiency.

\section{CONSIDERACIONES GENERALES YEPIDEMIOLOGÍA}

El vitiligo es la despigmentación cutánea adquirida más común, con una tasa de prevalencia entre el $0,1 \%$ y el $2 \%$ en adultos y niños ${ }^{(1)}$. Alrededor del 1 $\%$ de la población mundial tiene vitiligo y es India el país con mayor incidencia en el mundo, con un $8,8 \%$ de personas afectadas ${ }^{(2)}$. Clínicamente, se caracteriza por el desarrollo de máculas acrómicas relacionadas con la pérdida selectiva de melanocitos, localizadas frecuentemente alrededor de los orificios y en las prominencias óseas, donde hay mayor riesgo de sufrir traumatismos en la piel que las recubre. No tiene predilección según la raza o el sexo y puede desarrollarse a cualquier edad, aunque es más frecuente en las dos primeras décadas de la vida. El 50 $\%$ de los casos se presentan antes de los 20 años ${ }^{(3)}$.
Aunque la mayoría de los casos son esporádicos, en el $20 \%$ se reportan familiares afectados de primer grado de consanguinidad ${ }^{(4)}$. Según la distribución, la extensión y el número de parches, se divide en vitiligo segmentario (que se extiende a lo largo del curso de un nervio) y no segmentario, el que, a su vez, se subdivide en generalizado (que se extiende ampliamente por la superficie corporal), acrofacial, de mucosas, universal y menor ${ }^{(1)}$. La distinción entre el vitiligo segmentario y el no segmentario puede afectar el pronóstico en términos de resistencia a la repigmentación en el primero ${ }^{(5)}$. Su curso natural es impredecible; la mayoría de los casos cursan con períodos largos de estabilidad intercalados con otros de progresión de la enfermedad.

\section{ETIOPATOGÉNESIS}

Los mecanismos exactos de la fisiopatología del vitiligo siguen siendo poco claros. Se han planteado varias teorías para explicar la etiología de esta entidad, entre las que se destacan: la teoría genética, la inmunitaria, la neurogénica, la bioquímica, la de la melanocitorragia y la de convergencia (tabla 1). La más convincente parece ser esta última, que reúne todos los factores causantes o activadores que pueden actuar independiente o sinérgicamente para alterar la pigmentación de los melanocitos ${ }^{(2)}$.

El principio clave de la repigmentación es la repoblación de parches despigmentados con melanocitos activos capaces de migrar y producir melanina en los sitios afectados por el vitiligo. Probablemente, su principal fuente son los melanocitos amelanóticos de las partes bajas y medias de la vaina radicular externa, los cuales se salvan de la destrucción mediada por las células $\mathrm{T}$ al no expresar los antígenos asociados con el vitiligo, fenómeno conocido como privilegio inmunitario. Sin embargo, se encuentra otro reservorio potencial en las células localizadas en la zona perilesional ${ }^{(4)}$. La repigmentación espontánea es poco común y ocurre ocasionalmente en áreas fotoexpuestas de pacientes jóvenes; el patrón más común es el de tipo perifolicular (6).

\section{ALTERACIONES ASOCIADAS CON EL VITILIGO}

Las asociaciones cutáneas más frecuentemente reportadas con el vitiligo son: leucotriquia (45\%), seguida por la aparición prematura de canas (37\%), el nevo 
con halo $(5 \%)$ y la alopecia areata (10 \%). Otras asociaciones menos frecuentes son: morfea, dermatitis herpetiforme, nevo melanocítico congénito gigante, urticaria crónica, erupción solar polimorfa y psoriasis vulgar confinada a los parches de vitiligo ${ }^{(7)}$. Puede ocurrir despigmentación de tipo vitiligo en pacientes con melanoma, al parecer como resultado de una reacción mediada por las células $\mathrm{T}$ contra los antígenos de las células tumorales que presentan una reacción cruzada con los melanocitos. La amelanosis alrededor del tumor primario semeja un nevo con halo, pero la despigmentación de tipo vitiligo puede aparecer en sitios distantes al melanoma ${ }^{(8)}$.

En cuanto a las enfermedades autoinmunitarias sistémicas asociadas de forma importante al vitiligo, tenemos la tiroiditis de Hashimoto, la enfermedad de Graves, la diabetes mellitus de tipo $1^{(9,10)}$, la anemia perniciosa, la enfermedad de Adisson y, en menor proporción, el lupus eritematoso sistémico y la artritis reumatoide.

En un estudio retrospectivo de Ohguchi, et al., sobre los factores de riesgo y las reacciones al tratamiento en pacientes japoneses con vitiligo, se encontraron como factores de riesgo la disfunción tiroidea y la diabetes mellitus de tipo 1. Específicamente para el tipo segmentario, los anticuerpos antinucleares y la edad de inicio menor de 14 años son factores significativos. Para los tipos generalizados y localizados, no hubo factores de riesgo estadísticamente significativos (11).

La piel, el folículo piloso, la mucosa oral, las meninges, el oído interno y el ojo están íntimamente relacionados, ya que, durante la embriogénesis en la cresta neural, se forman las células precursoras de los melanocitos que, finalmente, migran a cada uno de estos lugares. Algunas enfermedades oculares y auditivas se han relacionado con el vitiligo, posiblemente, debido

Table 1. Teorías sobre los factores etiopatogénicos del vitiligo

\begin{tabular}{|c|c|}
\hline Teorías & Descripción \\
\hline Genética & $\begin{array}{l}\text { Hay asociación de antecedentes familiares y personales, hasta } \\
\text { en } 20 \% \text { de los pacientes caucásicos }{ }^{(3)} \text {. }\end{array}$ \\
\hline Autoinmunitaria & $\begin{array}{l}\text { Diferentes loci (MHC, CTLA4, PTPN22, MBL2 y NALP1) } \\
\text { relacionados con la autoinmunidad y el vitiligo generalizado, } \\
\text { generan anticuerpos contra los antígenos de melanocitos y } \\
\text { células T citotóxicas; estos anticuerpos inducen la destrucción } \\
\text { de melanocitos en la piel perilesional, lo que se relaciona con } \\
\text { la persistencia del vitíligo }{ }^{(4)} \text {. }\end{array}$ \\
\hline Sistema inmunológico hiperreactivo & $\begin{array}{l}\text { Hay sobreproducción de citocinas proinflamatorias (como TNF- } \\
\text { a, IL-6 e IL-2) y hay células Th17 positivas que infiltran la dermis } \\
\text { superior; esto sugiere que citocinas como la IL-1a, la IFN-y, la } \\
\text { IL-10 y la IL17A, asociadas con dichas células, intervienen en la } \\
\text { desregulación de los melanocitos }{ }^{(6)} \text {. }\end{array}$ \\
\hline Daño neurogénico & $\begin{array}{l}\text { Las terminaciones nerviosas cercanas a los melanocitos } \\
\text { secretan un mediador neuroquímico citotóxico para ellos, lo } \\
\text { cual se evidencia por la degeneración axonal que afecta los } \\
\text { nervios de la piel vitiliginosa }{ }^{(4)} \text {. }\end{array}$ \\
\hline Anormalidades bioquímicas & $\begin{array}{l}\text { La disminución de antioxidantes, como la catalasa, el ubicuinol } \\
\text { y la vitamina E, altera la capacidad de los queratinocitos de } \\
\text { contrarrestar las especies reactivas de oxígeno }{ }^{(1)} \text {, por lo cual } \\
\text { se ejerce una acción citotóxica directa e indirecta contra los } \\
\text { melanocitos, mediante mayor producción de catecolaminas. } \\
\text { Esto puede explicar por qué el estrés mental facilita la } \\
\text { aparición de lesiones por medio de la activación del eje } \\
\text { hipotálamo-hipófiso-suprarrenal }{ }^{(2)} \text {. }\end{array}$ \\
\hline Melanocitorragia & $\begin{array}{l}\text { Se ha postulado que el vitiligo no segmentario podría deberse a } \\
\text { un desprendimiento crónico de melanocitos, de origen } \\
\text { traumático, principalmente por roce mecánico de la piel sana. } \\
\text { Algo que apoya esto es que hasta } 31 \% \text { de quienes padecen esta } \\
\text { enfermedad presentan el fenómeno de Koebner }{ }^{(1)} \text {. }\end{array}$ \\
\hline
\end{tabular}

FNT- $\alpha$ : factor de necrosis tumoral alfa; IFN-ү: interferón gamma; IL: interleucina; Th: células T ayudadoras. 
Table 2. Trastornos oculares y auditivos en pacientes con vitiligo

\begin{tabular}{|c|c|}
\hline Trastornos oculares & Descripción \\
\hline Síndrome de Vogt-Koyanagi-Harada & $\begin{array}{l}\text { Panuveítis bilateral con desprendimiento de retina y } \\
\text { alteraciones neurológicas, cutáneas (vitiligo, alopecia, } \\
\text { poliosis) y auditivas (pérdida auditiva coclear, vértigo). } \\
\text { Enfermedad autoinmunitaria cuyo blanco inmunológico es el } \\
\text { melanocito }{ }^{(11,12)} \text {. }\end{array}$ \\
\hline Glaucoma de ángulo abierto & $\begin{array}{l}\text { Se encontró en } 57 \% \text { de } 42 \text { pacientes con vitiligo sin } \\
\text { tratamiento con corticoides }{ }^{(13)} \text {. }\end{array}$ \\
\hline Alteración conjuntival y de la película lagrimal & $\begin{array}{l}\text { La prueba de Schirmer y el tiempo más corto de ruptura de la } \\
\text { película lacrimal estaban alterados en los casos de vitiligo } \\
\text { periocular y acrofacial }^{(14)} \text {. }\end{array}$ \\
\hline Uveítis & $\begin{array}{l}\text { Se presentó en } 4 \% \text { de } 150 \text { pacientes con vitiligo, entre ellos, } \\
\text { uno con panuveítis, dos con uveítis anterior y tres con uveítis } \\
\text { intermedia, sin ningún caso en el grupo control }{ }^{(15)} \text {. }\end{array}$ \\
\hline Vitiligo coroideo primario & $\begin{array}{l}\text { Parches extensos de hipopigmentación coroidea, sin } \\
\text { compromiso retiniano, en pacientes con vitiligo }{ }^{(16)} \text {. }\end{array}$ \\
\hline Hipopigmentación del iris & $\begin{array}{l}\text { Parches hipopigmentados en } 23 \text { a } 33 \% \text { de los casos de vitiligo } \\
\text { (17). }\end{array}$ \\
\hline Alteraciones pigmentarias de la retina & $\begin{array}{l}\text { Hipopigmentación del epitelio retiniano y atrofia de los } \\
\text { fotorreceptores con nictalopía secundaria en } 25 \% \text { de los } \\
\text { pacientes con vitiligo } \\
\text { Retinitis pigmentaria, sin disminución del espesor de la capa de } \\
\text { fibras nerviosas de la retina }{ }^{(18)} \text {. }\end{array}$ \\
\hline Trastornos electrofisiológicos retinianos & $\begin{array}{l}\text { En } 21 \text { pacientes con vitiligo, el electrorretinograma (para } \\
\text { evaluar cambios en la corriente de la retina, secundarios a un } \\
\text { estímulo luminoso) demostró alteración de la electrofisiología } \\
\text { de la retina, con disminución de la amplitud de las ondas a y b, } \\
\text { con las cuales se evalúan las corrientes eléctricas de los } \\
\text { fotorreceptores (conos, bastones y células ganglionares) y de } \\
\text { las células bipolares, respectivamente }{ }^{(16)} \text {. }\end{array}$ \\
\hline Trastornos auditivos & Descripción \\
\hline Hipoacusia neurosensorial & $\begin{array}{l}\text { En el vitiligo, simultáneamente con la pérdida de los } \\
\text { melanocitos epidérmicos, se pierden células del oído interno } \\
\text { que contienen melanina, lo cual abole su función preventiva y } \\
\text { conduce a pérdida de la audición neurosensorial. }{ }^{(19)} \text {. }\end{array}$ \\
\hline
\end{tabular}

a la agresión contra los melanocitos presentes en estos órganos sensitivos.

Generalmente, los pacientes no tienen síntomas oculares, pero pueden presentar anormalidades pigmentarias del iris y la retina, anormalidades en la coroides (30 \%), iritis ( $5 \%$ ) y nevos con halo coroideo como hallazgo infrecuente. La agudeza visual no se afecta y pueden ocurrir exoftalmos cuando se asocia con la enfermedad de Graves. En el síndrome de Vogt-Koyanagi Harada, los pacientes presentan vitiligo, poliosis, alopecia, panuveítis, meningitis aséptica, hipoacusia y tinnitus. Este síndrome es raro, autoinmunitario y mediado por células T. Otra entidad asociada, con pocos casos en la literatura, es el síndrome de Alezzandrini, cuya etiología está poco esclarecida (al parecer, es de origen autoinmunitario) y se presenta con vitiligo, poliosis, sordera y retinitis unilateral ${ }^{(2)}$. En la tabla 2 se resumen las alteraciones oculares y auditivas relacionadas con el vitiligo.

Entonces, son muchas las enfermedades oftalmológicas asociadas frecuentemente, hasta en un $66 \%$ de los casos con vitiligo; por tanto, idealmente, estos pacientes requieren siempre un examen oftalmológico que incluya agudeza visual, tonometría y prueba de Schirmer, y una valoración auditiva de rutina ${ }^{(12)}$. 


\section{MÉTODOS DE MEDICIÓN DE LA EXTENSIÓN O GRAVEDAD DEL VITILIGO}

La evaluación clínica del vitiligo implica una estimación de la superficie corporal afectada. Los métodos mejor validados para evaluar la gravedad y la repigmentación de las lesiones de vitiligo durante el seguimiento, son el VASI (Vitiligo Area Scoring Index, por sus siglas en inglés) y el VETFa (Vitiligo European Task Force Assessment, por sus siglas en inglés). Ambos miden, con gran precisión, la despigmentación y la reacción al tratamiento con la fototerapia UVB de banda estrecha (UVB-BE) ${ }^{(13)}$.

Como diferencias entre ambas escalas de medición están que el VETFa evalúa las lesiones de las manos y los brazos en un mismo segmento, mientras que el VASI lo hace por separado, considerando que las manos son, por lo general, resistentes al tratamiento. Para el VETFa, las lesiones se examinan con la luz de Wood, lo que hace más complejo su uso.

La ejecución de estos métodos consume tiempo. Por esta razón, en 2016, se introdujo un nuevo sistema de puntuación para evaluar más ágilmente el grado de afectación cutánea por el vitiligo, el puntaje de extensión del vitíligo (VES, por sus siglas en inglés). Al compararlo con el VASI, este nuevo instrumento de medición permite evaluar de forma estandarizada, con precisión y facilidad la superficie corporal afectada, lo que lo convierte en una herramienta prometedora para medir la extensión del vitiligo en los ensayos clínicos y en la práctica diaria ${ }^{(14)}$.

Además de estos métodos de medición, se han descrito herramientas que usan imágenes digitalizadas, que son ideales para el seguimiento de los pacientes con vitiligo y la medición de la reacción al tratamiento. Esta evaluación mucho más objetiva se hace con imágenes en dos y tres dimensiones, con lo cual se obtiene una evaluación real de la progresión o la estabilización de la enfermedad ${ }^{(15)}$.

En los últimos meses, se desarrolló una herramienta que permite a los pacientes autoevaluarse con la escala SA-VES (Self-Assessment-Vitiligo Extent Score, por sus siglas en inglés). Los resultados demostraron una excelente fiabilidad y correlación con la VES, que es su contraparte, lo que los llevó a concluir que este método de evaluación orientado al paciente es útil para evaluar la extensión o la gravedad del vitiligo ${ }^{(16)}$.

\section{TRATAMIENTO}

Durante la evaluación de los pacientes, es importante considerar la edad, las enfermedades preexistentes, en particular las autoinmunitarias, las mediciones previas de la afectación de la superficie corporal y los parámetros objetivos y subjetivos, incluida la fase en que se encuentra la enfermedad. Es importante considerar que, a menudo, el tratamiento se extiende por un largo período y los pacientes suelen sentirse frustrados por el fracaso de los tratamientos previos ${ }^{(17)}$.

Debido a que el vitiligo impacta la calidad de vida, se recomienda el tratamiento diligente, preferentemente de inicio temprano en la fase activa de la enfermedad (18). La fase inflamatoria del vitiligo mediada inmunológicamente necesita definirse mejor, para desarrollar enfoques específicos dirigidos a ella. En la mayoría de los casos, esta fase es silenciosa y solo se revela cuando las biopsias de piel se toman en los márgenes de las lesiones que estén progresando. El vitiligo estable necesita un tratamiento para regenerar los melanocitos del folículo piloso o de los precursores interfoliculares ${ }^{(5)}$. Las modalidades actuales de tratamiento se enfocan principalmente en el vitíligo activo y buscan aumentar la repigmentación y detener la progresión de la enfermedad. Los tratamientos conservadores incluyen: corticosteroides tópicos, sistémicos e intralesionales, inmunomoduladores, antioxidantes orales y tópicos, análogos de la vitamina D, análogos de la melanotropina, fotoquimioterapia, que combina psoraleno con UVA, UVB de banda estrecha y de banda ancha, KUVA, que combina kelina con UVA, luz y láser de excímero, $\mathrm{y}$, por último, todo el arsenal quirúrgico con buen nivel de evidencia en el manejo de la enfermedad ${ }^{(1)}$.

El estímulo terapéutico, sea rayos ultravioletas UV, corticosteroides $\mathrm{u}$ otro, genera cambios que intervienen en el control, el metabolismo y la eliminación de sustancias tóxicas para los melanocitos e inmunomodulan su autodestrucción. Además, impulsan el reclutamiento de los melanocitos a partir de aquellos inactivos derivados de los folículos pilosos que se dividieron, proliferaron y, en el proceso de la activación, adquirieron todas las proteínas estructurales y enzimáticas requeridas para la melanogénesis ${ }^{(4)}$.

También, se debe considerar el tipo de vitiligo, pues, como cada tipo se produce por un mecanismo diferente, la UVB-BE es efectiva para el vitiligo generalizado, la vitamina D tópica para el localizado y los microinjertos lo son para el segmentario y el localizado ${ }^{(4)}$. La UVB-BE se ha convertido en el tratamiento de primera línea para el vitiligo generalizado. Todas las fototerapias funcionan por el daño que produce la luz ul- 
travioleta a los queratinocitos; llevan a la liberación de citocinas que estimulan la migración de melanocitos y a sus precursores a diferenciarse y migrar hacia la epidermis despigmentada ${ }^{(4)}$. Posiblemente, la fototerapia UVB desempeña un papel beneficioso adicional en el tratamiento del vitiligo, como inductor de la síntesis endógena de vitamina $D$, la cual se sintetiza principalmente por la radiación UVB, que contribuye a más del $90 \%$ de la concentración sérica de $25(\mathrm{OH}) \mathrm{D}^{(19)}$.

Las lesiones más sensibles a la fototerapia son las localizadas en el rostro, el cuello y el tronco; y las más resistentes son las de las manos, los pies, los codos y las rodillas ${ }^{(18)}$. Algunos estudios muestran un aumento de la eficacia de la fototerapia UVB-BE asociada con el suplemento oral de antioxidantes, que incluyen ácido alfalipoico, vitaminas C y E y ácidos grasos poliinsaturados, sustentados en la reparación del daño por estrés oxidativo ${ }^{(20)}$, inducido por la radiación UV en sí misma. Los ensayos abiertos sugieren que la administración oral o tópica de múltiples antioxidantes detiene la progresión de la enfermedad y promueve la repigmentación ${ }^{(16) .}$

Otras opciones terapéuticas incluyen la despigmentación de la piel pigmentada, cuando esta abarca un menor porcentaje que la acrómica; también la cirugía, cuando los tratamientos médicos hayan fallado o en ciertas variedades de vitiligo, especialmente el focal y estable; es decir, en el que no se produzca el fenómeno de Koebner y la enfermedad no haya progresado durante un año; con la cual se han visto resultados promisorios, especialmente cuando son seguidas por la exposición a fuentes de radiación UVB o UVA ${ }^{(4)}$.

En los últimos años han cobrado mayor interés los tratamientos combinados, ya que actúan sinérgicamente, mejorando la eficacia y acortando la duración y la dosis total de exposición a la irradiación. El esquema más utilizado combina UVB-BE con inhibidores de la calcineurina, análogos tópicos de la vitamina $\mathrm{D}$, corticosteroides tópicos y antioxidantes ${ }^{(6)}$. Ohguchi, et al., informaron que el enfoque combinado de UVB-BE y vitamina D tópica fue eficaz para el vitiligo localizado; esta disminuyó el número de células de Langerhans y aumentó las células T reguladoras, lo que sugiere que esta combinación induce inmunosupresión ${ }^{(11)}$.

Los análogos de la vitamina D, como el calcipotriol, controlan la proliferación y la diferenciación celular, lo cual, aunado a la fototerapia, causa hiperpigmentación como un efecto secundario. Por otra parte, la vitamina D y sus análogos están involucrados en el control de múltiples vías intracelulares responsables de la síntesis de la melanina, de la supervivencia de los melanocitos y de la supresión de la reacción inmunitaria.
Además, protegen la unidad de melanina epidérmica y restauran la integridad melanocítica mediante sus propiedades antioxidantes. Todos estos hallazgos estimulan la investigación con compuestos de la vitamina $\mathrm{D}$ en los pacientes con vitiligo, abriendo así nuevas perspectivas en el tratamiento de la despigmentación (4,5).

\section{Vitamina D}

La vitamina $\mathrm{D}$ no es una vitamina, ya que no cumple como tal la definición de "elemento esencial en la dieta"; ciertamente, es una hormona. Sin embargo, se puede obtener por la dieta, con suplementos, o por la síntesis de la piel al exponerse a la radiación UVB. La 25-hidroxivitamina D, con una vida media de dos semanas, aproximadamente, es el principal metabolito circulante de la vitamina $\mathrm{D}$ y es el indicador más apropiado de los niveles séricos de vitamina $\mathrm{D}$ en los seres humanos ${ }^{(21)}$.

\section{Obtención y síntesis}

Las dos fuentes principales de la vitamina D son los suplementos dietéticos exógenos y la producción endógena de la piel por medio de la exposición a la luz solar, específicamente, de los queratinocitos basales, suprabasales y fibroblastos dérmicos. En la figura 1 se describe la síntesis de la vitamina $\mathrm{D}^{(22)}$.

La producción de la vitamina $\mathrm{D}_{3}$ en la piel depende de la exposición al sol, de la latitud, del tipo de prendas de vestir, del uso de protector solar, del fototipo de piel y de la dieta. En general, los niveles de 25(OH)D son menores en las latitudes más altas y en los fototipos de piel más oscuros. No obstante, en Norteamérica, la deficiencia de vitamina $\mathrm{D}$ es poco frecuente, porque la leche generalmente contiene suplemento de vitamina D, pero la insuficiencia es aún común ${ }^{(23)}$.

En Estados Unidos y Europa, del $10 \%$ al $20 \%$ de las necesidades de vitamina $\mathrm{D}$ del organismo humano puede obtenerse por la dieta, en adecuadas condiciones de vida. Los principales alimentos que la contienen son: el salmón, las sardinas, la caballa, el atún, el aceite de hígado de bacalao, la yema de huevo, la comida fortificada, la leche, el jugo de naranja, el yogur, la mantequilla, el queso y el cereal. Algunos países fortalecen los alimentos con vitamina $\mathrm{D}$, como el jugo de naranja, la leche, el yogur y el cereal ${ }^{(24)}$.

La ingestión diaria recomendada en la infancia temprana se estima en $400 \mathrm{UI}$ al día; sin embargo, después de 1 año, la ingestión diaria recomendada es de 600 UI y, después de los 71 años, es de 800 UI. El uso de suplementos orales de vitamina D puede ser 
suficiente para prevenir enfermedades óseas graves, como la osteomalacia o el raquitismo, pero no la osteoporosis u otras enfermedades que se cree están relacionadas con la vitamina $\mathrm{D}^{(22)}$.

Otros posibles determinantes del estado de la vitamina D incluyen el sexo, la edad, el índice de masa corporal (IMC), la actividad física, la ingestión de alcohol y los polimorfismos genéticos. Las mujeres tienen un mayor riesgo de presentar deficiencia de vitamina $\mathrm{D}$, la edad avanzada se correlaciona negativamente con el estado de la vitamina D y un alto IMC y un bajo nivel de actividad física también se asocian con bajas concentraciones de $25(\mathrm{OH}) \mathrm{D}^{(22)}$.

Según Harinarayan, et al., factores como el ángulo cenital solar, la hora del día, la estación del año, la cantidad de ozono, la cobertura de las nubes, la latitud y la altitud influyen en la cantidad de radiación UVB en un lugar particular, lo cual, a su vez, determina la producción de vitamina $\mathrm{D}_{3}$ cutánea. La consulta de expertos de la Organización de las Naciones Unidas para la Agricultura y la Alimentación y la Organización Mundial de la Salud (FAO/OMS) indica que una gran cantidad de luz solar en la mayoría de las regiones del mundo entre los $42^{\circ} \mathrm{N}$ y los $42^{\circ} \mathrm{S}$ permite una adecuada síntesis cutánea de la vitamina $\mathrm{D}^{(23,25)}$.

Por otro lado, la síntesis cutánea de vitamina D no requiere baños de sol; únicamente 15 minutos en promedio de exposición de los brazos y las piernas en un día soleado, dos o tres veces por semana, según la dosis eritematosa mínima, es suficiente para generar el equivalente a 2000 a 4000 UI de vitamina D, aproximadamente ${ }^{(26)}$. Sin embargo, falta información sobre la exposición solar óptima para la suficiencia de vitamina $\mathrm{D}^{(22)}$.

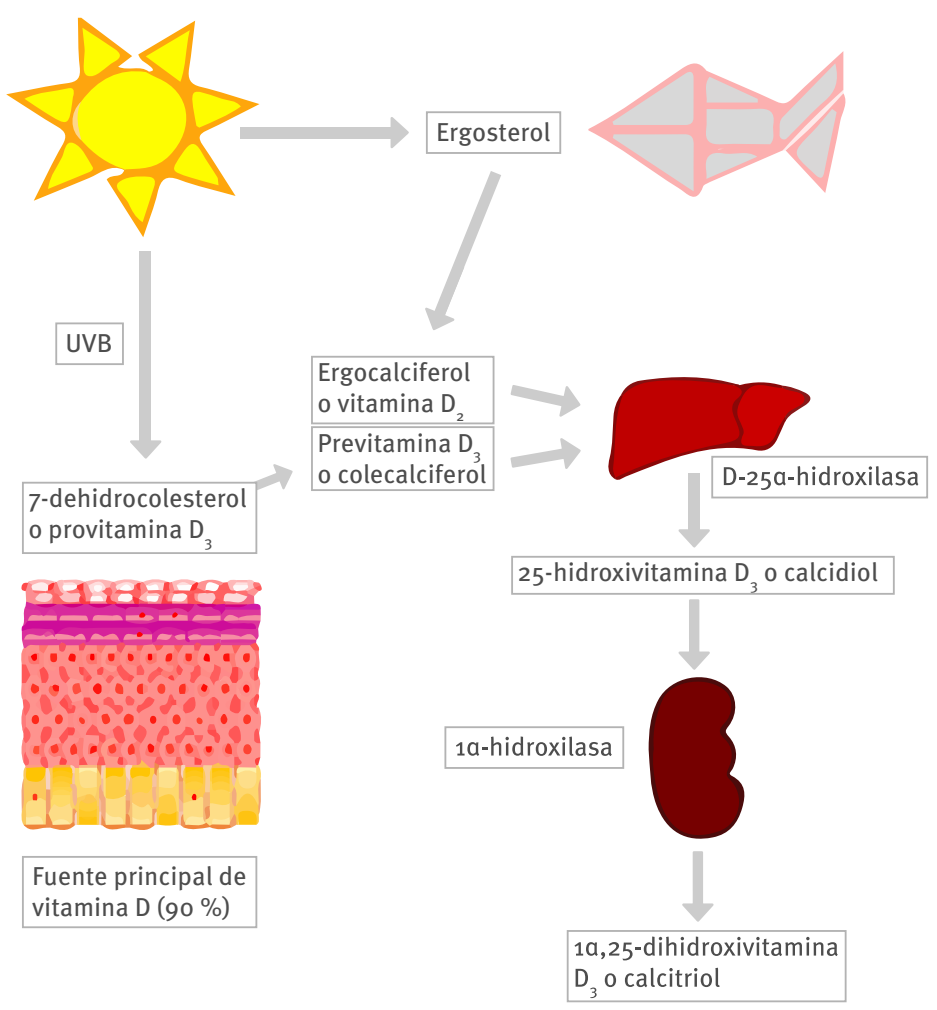

Figura 1. Síntesis de la vitamina D. La radiación ultravioleta B actúa sobre el 7-dehidrocolesterol o provitamina $\mathrm{D}_{3}$, que se encuentra en la piel, la cual es la principal fuente de vitamina $\mathrm{D}$, convirtiéndola en previtamina $\mathrm{D}$ o colecalciferol. Asimismo, la luz solar actúa sobre el ergosterol que se halla en algunos alimentos, dándole paso al ergocalciferol, o vitamina $\mathrm{D}_{2}$. Tanto el ergocalciferol como el calciferol son transformados en el hígado a 25-hidroxivitamina $\mathrm{D}_{3}$, o calcidiol, por medio de la enzima D-25 $\alpha$-hidroxilasa; posteriormente, se transforma en el riñón a 1a-25-dihidroxivitamina $\mathrm{D}_{3}$, o calcitriol, por medio de la enzima 1a-hidroxilasa. 


\section{Funciones}

La vitamina D, o calcitriol, es verdaderamente una hormona liposoluble que tiene funciones endocrinas, paracrinas y autocrinas ${ }^{(27)}$. Sin embargo, su acción va mucho más allá de la regulación del equilibrio de calcio, fósforo, paratohormona y el metabolismo óseo, ya que algunas de sus actividades y de sus metabolitos naturales garantizan el funcionamiento adecuado de los principales órganos humanos, incluida la piel ${ }^{(3)}$. Esto último ha llevado a pensar en un papel diferente, como en la disminución del riesgo de varias enfermedades crónicas, como carcinomas, enfermedades autoinmunitarias, infecciosas y cardiovasculares. Asimismo, debido a la síntesis cutánea de vitamina D, se apunta hacia un papel inmunomodulador que ha

Table 3. Funciones de la vitamina D

\begin{tabular}{|c|c|}
\hline Función & Descripción \\
\hline Endocrina & $\begin{array}{l}\text { En la homeostasis del calcio sérico, participa nivelando la } \\
\text { absorción del intestino o la extracción de los huesos }{ }^{(35)} \text {. } \\
\text { Regulación del equilibrio de calcio, fósforo y paratohormona, y } \\
\text { del metabolismo óseo }{ }^{(3)}\end{array}$ \\
\hline Paracrinos y autocrinos & Regulación de la secreción hormonal ${ }^{(35)}$. \\
\hline Inmunorreguladora & $\begin{array}{l}\text { Inmunidad innata: los monocitos promueven la unión de la } \\
1,25(\mathrm{OH}) 2 \mathrm{D} \text { a su receptor VDR endógeno, como reacción a } \\
\text { Mycobaterium tuberculosis, modulando la expresión génica } \\
{ }^{(39)} \text {. } \\
\text { Inmunidad celular: se incrementan el tamaño celular, el } \\
\text { número de dendritas y la cantidad de tirosinasa } \\
\text { inmunorreactiva }{ }^{(36)} \text {. }\end{array}$ \\
\hline Antimicrobiana & $\begin{array}{l}\text { Regula el procesamiento de las glucosilceramidas de cadena } \\
\text { larga, importantes para la formación de la barrera cutánea }{ }^{(32)} \text {. }\end{array}$ \\
\hline Efecto antiproliferativo y antinflamatorio & $\begin{array}{l}\text { Sobre las células B y T, reduce la expresión del complejo } \\
\text { principal de histocompatibilidad de clase II, e inhibe la } \\
\text { secreción de citocinas proinflamatorias (IL-1, IL-2, IL-6, IFN y, } \\
\text { FNTa, IL-12 e IL-17), lo que impide la función de Th1 y Th17 }{ }^{(29)} \text {. }\end{array}$ \\
\hline Diferenciación y proliferación celular & $\begin{array}{l}\text { Actúa sobre en los enterocitos, osteoblastos, células de la } \\
\text { glándula paratiroides, queratinocitos, sebocitos, fibroblastos, } \\
\text { melanocitos y células ováricas }{ }^{(40)} \text {. }\end{array}$ \\
\hline Efecto anabólico & $\begin{array}{l}\text { En el músculo esquelético, se relaciona con el rendimiento } \\
\text { físico }{ }^{(6)} \text {. }\end{array}$ \\
\hline Neuroprotector & $\begin{array}{l}\text { Aumento en la producción y liberación de neurotrofinas, la } \\
\text { síntesis de neuromediadores, la homeostasis del calcio } \\
\text { intracelular y la prevención del daño oxidativo al tejido } \\
\text { nervioso. Los estudios clínicos sugieren que la deficiencia de } \\
\text { vitamina D puede llevar a un mayor riesgo de enfermedad del } \\
\text { sistema nervioso central, en particular la esquizofrenia y la } \\
\text { esclerosis múltiple }{ }^{(72)} \text {. }\end{array}$ \\
\hline Prevención del cáncer & $\begin{array}{l}\text { Inhibe el crecimiento y la diferenciación de las células } \\
\text { tumorales, y favorece su apoptosis }{ }^{(42)} \text {. }\end{array}$ \\
\hline Melanogénesis & $\begin{array}{l}\text { La reacción de los melanocitos ante estímulos melanogénicos } \\
\text { está modulada por enzimas reguladoras y factores de } \\
\text { transcripción dependientes del calcio. }\end{array}$ \\
\hline Factor de transcripción & $\begin{array}{l}\text { Regula la expresión de más de } 3.000 \text { genes diana en el genoma } \\
\text { humano }^{(43)} \text {. }\end{array}$ \\
\hline Efectos en otros órganos & $\begin{array}{l}\text { Con su proteína de unión, la vitamina D actúa por medio de } \\
\text { mecanismos genómicos sobre el páncreas, el músculo liso } \\
\text { vascular y los monocitos, y mediante otros no genómicos, en } \\
\text { otros tejidos diana que expresan receptores de la vitamina D, } \\
\text { como el hueso, el intestino y la glándula paratiroidea }{ }^{\left({ }^{36)}\right.} \text {. }\end{array}$ \\
\hline
\end{tabular}

FNT- $\alpha$ : factor de necrosis tumoral alfa; IFN-ү: interferón gamma; IL: interleucina; $\mathrm{T}_{\mathrm{h}}$ 1: células T ayudadoras. 
abierto canales para descubrir sus efectos terapéuticos en enfermedades dermatológicas, como la dermatitis atópica, la psoriasis y el cáncer de piel ${ }^{(28)}$. En la tabla 3 se resumen las funciones de la vitamina D.

Todavía se desconoce el mecanismo mediante el cual la vitamina D ejerce sus efectos en los melanocitos. Se cree que la vitamina D está implicada en la fisiología de los melanocitos, coordinando citocinas melanogénicas (más probable endotelina-3 [ET-3]) y la actividad del sistema SCF/c-kit, que es uno de los reguladores más importantes de la viabilidad y maduración de los melanocitos ${ }^{(33)}$. Otro punto es que la forma activa de la vitamina $\mathrm{D}$ reduce la actividad apoptótica inducida por la UVB en los queratinocitos y en los melanocitos, mediante la producción de interleucina 6 y la formación de esfingosina-1-fosfato ${ }^{(38)}$.

\section{Déficit de vitamina D y asociación}

\section{con estados patológicos}

Paradójicamente, la misma radiación solar necesaria para la producción eficiente de la vitamina $\mathrm{D}$ es uno de los factores más dañinos para la piel. La UVB (280$320 \mathrm{~nm}$ ) provoca daños directos en el ADN, que, a su vez, genera cáncer de piel. Por tanto, a causa de las recomendaciones de disminuir la exposición solar, nos estamos viendo enfrentados a una deficiencia global de vitamina $\mathrm{D}^{(39)}$.

La OMS estima que la radiación UV se asocia con 60 ooo muertes prematuras por año, una pérdida de 1,5 millones de años de vida ajustados por discapacidad, 12,8 millones de cánceres de piel no melanoma y 200 ooo melanomas. Teniendo en cuenta esto, se debe buscar un adecuado equilibrio entre la fotoprotección extrema y la exposición solar desmesurada ${ }^{(22)}$.

El déficit de vitamina $\mathrm{D}$ se ha asociado con varias enfermedades infecciosas, como la tuberculosis; además, con enfermedades autoinmunitarias, como la diabetes mellitus de tipo 1, la enfermedad de Crohn y la esclerosis múltiple. También, se ha implicado en la salud cardiovascular y algunas neoplasias ${ }^{(32)}$, en enfermedades del sistema nervioso o de la reproducción, y en el dolor ${ }^{(22)}$. En la tabla 4 se expone la relación de las enfermedades dermatológicas con la vitamina D.

Los expertos coinciden en que se necesitan dosis diarias de, al menos, 1000 UI para lograr un efecto protector contra el cáncer y otras enfermedades, especialmente las autoinmunitarias; en estas últimas, se ha

Tabla 4. Enfermedades dermatológicas y su relación con la vitamina D

\begin{tabular}{|c|c|}
\hline Enfermedad & Asociación con la vitamina D \\
\hline \multirow{3}{*}{ Dermatitis atópica } & $\begin{array}{l}\text { La vitamina D resulta esencial para la estructura de la barrera } \\
\text { cutánea, al aumentar la profilagrina y la producción de lamela } \\
\text { lipídica }{ }^{(46)} \text {. } \\
\text { Su deficiencia se ha relacionado inversamente con la gravedad } \\
\text { de la enfermedad. }\end{array}$ \\
\hline & $\begin{array}{l}\text { En algunos ensayos controlados aleatorios, encontraron } \\
\text { mejoría de la dermatitis atópica con suplementos de vitamina D } \\
(47-51) \text {. }\end{array}$ \\
\hline & $\begin{array}{l}\text { En comparación con el placebo, el suplemento de vitamina D } \\
\text { durante un mes produjo una mejoría clínica y estadísticamente } \\
\text { significativa en el puntaje del EASI (Eczema Area and Severity } \\
\text { Index). Además, el cambio en la evaluación global del } \\
\text { investigador favoreció la vitamina D sobre el placebo. No hubo } \\
\text { efectos adversos en ninguno de los grupos }{ }^{\left({ }^{2}\right)} \text {. }\end{array}$ \\
\hline Psoriasis & $\begin{array}{l}\text { El calcitriol controla el aumento de la proliferación y regula la } \\
\text { diferenciación de los queratinocitos }{ }^{(45,53)} \text {. } \\
\text { La vitamina D inhibe la secreción de IL-2, IL-6, IL-8 e IFN- } y, \text { y } \\
\text { aumenta la producción de IL-10; al hacerlo, reduce la } \\
\text { proliferación de células T e induce la diferenciación reguladora } \\
\text { de células T }(54) \text {. } \\
\text { En la psoriasis, se pierde la capacidad de la síntesis cutánea de } \\
\text { vitamina } \mathrm{D}_{3} \text {. Existe una correlación negativa del nivel sérico de } \\
25 \text {-hidroxicolecalciferol, con el PASI ( }(\mathrm{r}=-0,43) \text { y la duración de } \\
\text { la psoriasis }(r=-0,53)^{(55)} \text {. }\end{array}$ \\
\hline Esclerosis sistémica & $\begin{array}{l}\text { La hipovitaminosis D es muy frecuente en la esclerosis } \\
\text { sistémica grave en un porcentaje relevante de pacientes; } \\
\text { además, menos de un tercio de aquellos que recibían } \\
\text { suplemento, alcanzaron niveles normales de } 25(\mathrm{OH}) \text { D. En este } \\
\text { estudio, además, se asoció estadísticamente con la tiroiditis } \\
\text { autoinmunitaria } \\
\text { (56). }\end{array}$ \\
\hline
\end{tabular}




\begin{tabular}{|c|c|}
\hline Enfermedad & Asociación con la vitamina D \\
\hline Alopecia areata & $\begin{array}{l}\text { El receptor de la vitamina } D \text { juega un papel importante en el } \\
\text { ciclo normal del folículo capilar. El raquitismo hereditario } \\
\text { resistente a la vitamina D es causado por mutaciones en el } \\
\text { receptor de la vitamina D. Según la naturaleza de la mutación } \\
\text { en el receptor, algunos de estos niños tienen, además, alopecia } \\
(57) \text {. } \\
\text { Se encontraron niveles significativamente más bajos de } \\
\text { vitamina } D \text {, al comparar casos y controles }{ }^{(58)} \text {. }\end{array}$ \\
\hline Lupus eritematoso sistémico & $\begin{array}{l}\text { La actividad de esta enfermedad se asoció con niveles bajos de } \\
\text { vitamina D. Tres grandes estudios con muestras de } 378,290, \text { y } \\
181 \text { pacientes, respectivamente, mostraron una fuerte } \\
\text { correlación entre los bajos niveles de } 25 \text {-hidroxivitamina D y la } \\
\text { actividad del lupus }{ }^{(59,60)} \text {. } \\
\text { Mok, et al., encontraron que la deficiencia de vitamina D es un } \\
\text { marcador de la actividad del lupus eritematoso sistémico, con } \\
\text { una especificidad comparable a la del ADN anti-bicatenario y la } \\
\text { del anti-C } 1 \text { lq }^{(61)} \text {. }\end{array}$ \\
\hline Erupción polimorfa lumínica & $\begin{array}{l}\text { El estado de la vitamina D se relacionó con erupción solar } \\
\text { polimorfa y sus análogos tópicos parecen desempeñar un papel } \\
\text { en el tratamiento y la prevención de esta alteración }{ }^{(62)} \text {. }\end{array}$ \\
\hline Infecciones de la piel & $\begin{array}{l}\text { La deficiencia de vitamina D afecta la expresión de CAMP y la } \\
\text { capacidad de los ratones para resistir la infección por } \\
\text { Streptococcus del grupo A }{ }^{(63)} \text {. } \\
\text { La vitamina D aumenta la inmunidad innata en infecciones por } \\
\text { Mycobacterium tuberculosis, induciendo la expresión del gen } \\
\text { péptido antimicrobiano catelicidina }(C A M P) \text {. La proteína } \\
\text { producida por este gen, LL-37, inhibe directamente las } \\
\text { micobacterias en cultivo líquido }{ }^{(64)} \text {. }\end{array}$ \\
\hline Queratosis actínica & $\begin{array}{l}\text { La vitamina } D \text { inhibe la proliferación de los queratinocitos in } \\
\text { vitro y regula su diferenciación. Polimorfismos del receptor de } \\
\text { vitamina } D \text { se vincularon con el desarrollo de queratosis } \\
\text { actínicas }{ }^{(65)} \text {. }\end{array}$ \\
\hline Carcinoma basocelular & $\begin{array}{l}\text { La vitamina D inhibe la vía de señalización de hedgehog en el } \\
\text { desarrollo de este carcinoma }{ }^{(66)} \text {. } \\
\text { Se encontró una correlación negativa entre el carcinoma } \\
\text { basocelular y el estado de vitamina D en múltiples estudios }{ }^{(67)} \text {. }\end{array}$ \\
\hline Micosis fungoide & $\begin{array}{l}\text { La deficiencia de vitamina D se ha relacionado con la micosis } \\
\text { fungoide. El polimorfismo del VDR se ha correlacionado } \\
\text { significativamente con este linfoma cutáneo }{ }^{(68)} \text {. }\end{array}$ \\
\hline Melanoma & $\begin{array}{l}\text { Algunos polimorfismos del VDR se han asociado con el } \\
\text { melanoma }{ }^{(69)} \text {. } \\
\text { Newton-Bishop, et al., encontraron un relación inversa entre } \\
\text { los niveles de } 25 \text {-hidroxivitamina } D \text { en el momento del } \\
\text { diagnóstico y el espesor del tumor, así como con el riesgo de } \\
\text { recaída del melanoma }{ }^{(70)} \text {. } \\
\text { La recaída del melanoma fue más común entre pacientes con } \\
\text { bajos niveles de vitamina }{ }^{(71)} \text {. }\end{array}$ \\
\hline
\end{tabular}

CAMP: péptido antimicrobiano catelicidina; EASI: Eczema Area and Severity Index; IFN-ү: interferón gamma; IL: interleucina; VDR: receptor de la vitamina D. 
demostrado que la deficiencia de vitamina D facilita la progresión de la enfermedad latente o manifiesta ${ }^{(21)}$.

\section{La situación en Colombia y en otras regiones del mundo}

Los datos sobre el estado de la vitamina D en Latinoamérica son escasos. En un estudio realizado en mujeres posmenopáusicas con osteoporosis se encontraron promedios séricos de 25(OH)D de $26 \mathrm{ng} / \mathrm{mL}$ en México, de 32,4 ng/mL en Brasil y de 30 ng/mL en Chile; los porcentajes por debajo de los $20 \mathrm{ng} / \mathrm{mL}$ fueron del $29 \%$, del $15 \%$ y del $19 \%$, respectivamente ${ }^{(67)}$.

En un estudio llevado a cabo en Argentina, la medición sérica de $25(\mathrm{OH}) \mathrm{D}$ se redujo de $20,8 \mathrm{ng} / \mathrm{mL}$ en el norte, en la latitud más baja, a 14,4 ng/mL en el sur, a mayor latitud. En un estudio realizado en Bogotá, se encontró que la prevalencia de déficit de vitamina $\mathrm{D}$ en mujeres posmenopáusicas era del $81 \%$ y el promedio sérico de $25(\mathrm{OH}) \mathrm{D}$ fue de $19,81 \mathrm{ng} / \mathrm{mL}^{(68)}$. Este resultado es menos favorable que el encontrado en países con estaciones climáticas y equivale al de otros países en Suramérica ${ }^{(23)}$ y en Pakistán (latitud $33^{\circ} \mathrm{N}$ ) ${ }^{(67)}$.

En la India, según Lips, se ha encontrado deficiencia de vitamina $\mathrm{D}$ en todos los grupos de edad y en ambos sexos, modificada por variables como: estado puberal, latitud, estación, raza y etnia, baja ingestión en la dieta, alteraciones hepáticas, renales o dermatológicas, alcoholismo y diversas condiciones reumatológicas e inflamatorias ${ }^{(23)}$. En la población turca, van der Meer, et al., demostraron que el estado de la vitamina D varía ampliamente de acuerdo con el color más oscuro de la piel, el uso de protectores solares, la ingestión insuficiente de vitamina $\mathrm{D}$ en la dieta y el hábito de usar ropa para cubrir la mayor parte del cuerpo ${ }^{(29)}$.

\section{RELACIÓN DEL VITILIGO CON LA VITAMINA D}

Los pacientes con vitiligo y bajas concentraciones de vitamina D constituyen un grupo de riesgo para formas de autoinmunidad. El origen de esta asociación radica en la capacidad de la vitamina D para inhibir la proliferación de las inmunoglobulinas, retardar la diferenciación de los precursores de las células B e inhibir la proliferación de células $\mathrm{T}$ ayudadoras $\left(\mathrm{T}_{\mathrm{h}} 1\right)$, capaces de producir citocinas y activar a los macrófagos. Se considera que los niveles bajos de vitamina $\mathrm{D}$ son uno de los factores ambientales que pueden aumentar la prevalencia de ciertas enfermedades autoinmunitarias, entre ellas, el vitíligo ${ }^{(31)}$.
Hay una cantidad considerable de datos que vinculan a la vitamina D con la etiopatogenia de las enfermedades autoinmunitarias, incluido el vitiligo, la cual ejerce sus efectos a través del gen del receptor de la vitamina $\mathrm{D}^{(24)}$. El mecanismo exacto por el cual la vitamina D afecta a la autoinmunidad aún es desconocido. Es difícil saber si los niveles bajos son la consecuencia o la causa de la enfermedad autoinmunitaria, si los pacientes con vitiligo son más propensos a la autoinmunidad secundaria o si la deficiencia de vitamina D es una causa contribuyente de inflamación autoinmunitaria ${ }^{(8)}$. Por esta razón, el seguimiento de los niveles séricos de $25(\mathrm{OH}) \mathrm{D}_{3}$ en los pacientes con vitiligo puede considerarse útil para determinar si hay autoinmunidad coexistente ${ }^{(28,69)}$.

En una revisión sistemática y metaanálisis que pretendía establecer si hay una relación entre la hipovitaminosis D y el vitiligo, Upala, et al., encontraron que la diferencia de medias en la concentración sérica de $25(\mathrm{OH}) \mathrm{D}$ entre los pacientes con vitiligo y los controles fue de $-7,45 \mathrm{ng} / \mathrm{mL}$, lo que los llevó a concluir que existe una fuerte evidencia de que el vitiligo se asocia significativamente con una menor concentración sérica de vitamina D; sin embargo, aún no se sabe si se trata de un factor causal para el vitiligo, de la misma manera que lo es para otras enfermedades autoinmunitarias ${ }^{(70)}$.

Saleh, et al., llevaron a cabo un estudio de casos y controles con 40 enfermos de vitiligo (20 con enfermedad autoinmunitaria sistémica y 20 sin ella) y 40 controles sanos con fototipo de piel, edad y sexo similares. Se les midió la 25(OH)D sérica y no se encontraron correlaciones significativas entre los valores obtenidos y la edad, la duración del vitiligo, la duración de las enfermedades autoinmunitarias asociadas o la superficie corporal afectada. Por lo tanto, concluyeron que en el vitiligo se presenta deficiencia sérica de $25(\mathrm{OH}) \mathrm{D}$ en pacientes con enfermedades autoinmunitarias sistémicas o sin ellas ${ }^{(19)}$.

Por otro lado, Saleh, et al., detectaron deficiencia de $25(\mathrm{OH}) \mathrm{D}$ en pacientes con vitiligo, en una relación muy significativa en comparación con los controles sanos (19). Xu, et al., también investigaron su deficiencia sérica en pacientes chinos con vitiligo, pero sus datos no revelaron una correlación entre los niveles de vitamina D y el inicio del vitiligo, aunque sí que con esta deficiencia se tenía un mayor riesgo de desarrollar enfermedades autoinmunitarias ${ }^{(30)}$.

Todavía se desconoce si la deficiencia de vitamina D puede asociarse con el desarrollo de vitiligo, como se hace en otras enfermedades autoinmunitarias. Doss, et al., llevaron a cabo un estudio en el Hospital Universitario Beni-Suef de Egipto, publicado en 2015, con el 
propósito de determinar el papel de la vitamina D en la patogénesis del vitiligo. Incluyeron 30 pacientes con vitiligo y 30 controles sanos, pareados por edad y sexo, a los cuales se les determinó el nivel sérico de $25(\mathrm{OH})$ $\mathrm{D}$ y se les tomaron biopsias de piel sobre las lesiones despigmentadas y sobre la piel normal, para determinar la expresión del gen del receptor de la vitamina D mediante la reacción en cadena de la polimerasa en tiempo real ${ }^{34}$ ). Encontraron que solo 10 (33,3 \%) pacientes con vitiligo tenían niveles séricos suficientes, 12 (40 \%) tenían niveles insuficientes y $8(26,7 \%)$ tenían niveles deficientes, mientras que la mayoría (96,7 \%) de los controles tenían niveles suficientes. La expresión de ARNm del gen del receptor de la vitamina D también disminuyó significativamente en la piel lesionada y en la piel sana de los pacientes, en comparación con los controles. Por todo lo anterior, concluyeron que la deficiencia de vitamina D influye en la extensión del vitiligo y podría contribuir a su patogénesis por medio de su función inmunomoduladora y su papel en la melanogénesis ${ }^{(34)}$.

Silverberg, et al., encontraron una disminución estadísticamente significativa de los niveles de $25(\mathrm{OH}) \mathrm{D}$ en casos de vitiligo y otras enfermedades autoinmunitarias, en comparación con los controles; más del 68,9 $\%$ de los pacientes tenían niveles séricos por debajo de los $30 \mathrm{ng} / \mathrm{mL}$. Confirmaron el papel de la ingestión de vitamina $\mathrm{D}$ en la prevención de enfermedades autoinmunitarias en familias propensas y concluyeron que, posiblemente, el suplemento de vitamina D ayudaría a controlar la actividad del vitiligo ${ }^{(8)}$.

Aksu, et al., encontraron que la prevalencia de deficiencia de $25(\mathrm{OH}) \mathrm{D}$ fue mayor en los casos de vitiligo (71\%) que en los controles sanos (33\%). No obstante, los hallazgos más importantes fueron la mayor prevalencia de la alopecia areata (91\%) y una correlación inversa significativa entre la gravedad de la enfermedad y la concentración sérica de la vitamina ${ }^{(71)}$. Por el contrario, $\mathrm{Xu}$, et al., en un estudio que incluyó a 171 pacientes chinos, no pudieron detectar diferencias significativas de los niveles de 25(OH)D entre los pacientes con vitiligo y los controles ${ }^{(30)}$.

En otro estudio llevado a cabo en el Hospital Universitario "Rey Khalid”, en Arabia Saudita, Khurrum, et al., se propusieron determinar el nivel sérico de vitamina $\mathrm{D}$ en los pacientes con vitiligo en comparación con los controles y revelar su posible asociación con la patogénesis de la enfermedad. Reclutaron 150 pacientes con vitiligo y 150 controles y midieron y correlacionaron la asociación entre los niveles de vitamina $\mathrm{D}$ y varios subgrupos de vitiligo, de acuerdo con la duración, el sitio de inicio y la edad, entre otras variables. Encontraron que los niveles séricos de los pacientes con vitiligo eran menores en los hombres, en el grupo de menor edad y en los no tratados con radiación ultravioleta, pero no encontraron diferencia entre los niveles de vitamina D de los casos y los controles. Concluyeron que el tipo y el curso del vitiligo y el área de superficie corporal no tienen relación con los niveles de vitamina $\mathrm{D}^{(18)}$.

En un estudio que incluyó 30 niños, se buscó determinar si los niveles séricos de $25(\mathrm{OH}) \mathrm{D}$ se encontraban disminuidos en aquellos con vitiligo y, también, se evaluaron los efectos del suplemento oral en niños con deficiencia de vitamina D. Se encontró que esta deficiencia era un importante problema entre los casos de vitiligo, así como en los controles; además, se observaron una diferencia significativa en el tamaño de la lesión en el sexto mes de tratamiento en quienes recibieron una combinación de vitamina D oral y tacrolimús tópico. A pesar de la limitación por tratarse de una muestra pequeña, concluyeron que la corrección de la deficiencia de vitamina D puede ser útil, no solo para prevenir los trastornos óseos, sino también en el mantenimiento de la homeostasis de las células de la piel. También, que posiblemente la cantidad óptima de vitamina $\mathrm{D}$ para apoyar la reacción inmunitaria podría ser diferente de la cantidad requerida para prevenir su deficiencia: más alta que la dosis estándar, pero no suficiente como para causar hipercalcemia. Además, este tratamiento podría ser más útil en niños con vitiligo que también tengan deficiencia de vitamina $\mathrm{D}^{(36)}$. Teniendo en cuenta que la vitamina D podría desempeñar un papel fisiológico en la melanogénesis inducida por la luz, Sehrawat, et al., estudiaron en 30 pacientes con vitiligo y en 30 controles, durante 12 semanas, los niveles de 25-hidroxivitamina D antes, durante y después de la radiación UVB-BE y su correlación con la pigmentación inducida. En las semanas o, 6 y 12, se calcularon las concentraciones de 25(OH)D en ambos grupos, además del VASI en los enfermos. Se observó una reducción significativa en la puntuación VASI después de 12 semanas de tratamiento y hubo correlación entre esta y el aumento de la vitamina. La fototerapia UVB-BE en pacientes con vitiligo induce un aumento de las hormonas estimulante del melanocito tipo alfa y la adrecorticotropina, además de los factores de crecimiento del fibroblasto tipo beta y endotelina, los cuales incrementan la melanogénesis por su estímulo paracrino. El estudio de Sehrawat, et al., sugiere que la vitamina D podría desempeñar un papel importante en la melanogénesis; sin embargo, se requieren estudios que explique cómo el aumento de la vitamina $\mathrm{D}$ con la fototerapia interviene en el proceso de repigmentación ${ }^{(37)}$. 
En 2014, en Turquía, Takci, et al., llevaron a cabo un estudio prospectivo de casos y controles, cuyo objetivo fue evaluar el metabolismo de la vitamina D en pacientes con vitiligo. Se incluyeron 44 pacientes con vitiligo vulgar y 43 controles sanos, y se midieron sus niveles plasmáticos de $25(\mathrm{OH}) \mathrm{D}$, parathormona, calcio, magnesio y fosfato. No se encontró ninguna diferencia significativa entre los dos grupos según la edad, el sexo o el fototipo de piel. En los pacientes con vitiligo, los niveles plasmáticos de $25(\mathrm{OH}) \mathrm{D}$ y el calcio estaban reducidos significativamente; también, la edad avanzada y las comorbilidades autoinmunitarias se asociaron significativamente con niveles menores ${ }^{(21)}$.

El papel de la vitamina D oral en el tratamiento del vitiligo no ha sido estudiado ampliamente. Finamor, et al., llevaron a cabo un estudio piloto para evaluar la eficacia y la seguridad del tratamiento prolongado con altas dosis de vitamina $\mathrm{D}_{3}$ en pacientes con psoriasis y vitiligo. Este estudio se basó en el hecho de que la autoinmunidad y la deficiencia de vitamina D están relacionadas y, a su vez, el metabolismo de la vitamina D en los pacientes afectados se asocia con la presencia frecuente de polimorfismos genéticos. Por tanto, la administración de altas dosis de vitamina $\mathrm{D}_{3}$ en pacientes con alteraciones autoinmunitarias puede compensar la resistencia heredada a sus efectos biológicos. Se trataron 16 pacientes con vitiligo con 35000 UI de vitamina $\mathrm{D}_{3}$ una vez al día durante 6 meses, en asociación con una dieta baja en calcio e hidratación. De los 16 pacientes, 14 presentaron del $25 \%$ al $75 \%$ de repigmentación, sin cambios significativos en los parámetros metabólicos, lo que indica que el tratamiento con dosis altas de vitamina $\mathrm{D}_{3}$ puede ser eficaz y seguro para esta enfermedad ${ }^{(72)}$.

\section{CONCLUSIÓN}

El vitiligo es una despigmentación patológica frecuente, y existe un especial interés en descubrir los factores que puedan ayudar a predecir su gravedad y los riesgos de su progresión, para encontrar aquellos que puedan ser modificables, con los que se pueda impactar favorablemente en la evolución de la enfermedad.

Se ha encontrado que los metabolitos naturales de la vitamina $\mathrm{D}$ contribuyen al funcionamiento adecuado de los principales órganos humanos, incluida la piel, en la cual desempeña un papel importante en la melanogénesis. Hasta ahora, los estudios sobre la relación entre el déficit de vitamina $\mathrm{D}$ y el desarrollo de vitiligo han tenido resultados contradictorios; sin embargo, existe una fuerte tendencia a vincular los niveles de la hormona con el vitiligo. De esta forma, se plantea una relación que podría orientar el entendimiento de la génesis, la fisiopatología, especialmente de la autoinmunidad, y de alguna forma, el tratamiento a futuro con suplemento de vitamina $\mathrm{D}_{3}$.

Se requieren más investigaciones a todo nivel que lleven a una mejor comprensión de este tema.

\section{REFERENCIAS}

1. Grimes PE. Vitiligo: pathogenesis, clinical features, and diagnosis. En: Tsao H (editor). UpToDate; 2016. Recuperado de: http://www.uptodate. com/contents/vitiligo-pathogenesis-clinical-features-and-diagnosis?source5search_result\&searc h5grimes1vitiligo\&selectedTitle54\%7E88.

2. Iannella G, Greco A, Didona D, Didona B, Granata G, Manno A, et al. Vitiligo: Pathogenesis, clinical variants and treatment approaches. Autoimmun Rev. 2016;15(4):335-43. doi: 10.1016/j.autrev.2015.12.006.

3. Alikhan A, Felsten LM, Daly M, Petronic-Rosic V. Vitiligo: a comprehensive overview. Part I. Introduction, epidemiology, quality of life, diagnosis, differential diagnosis, associations, histopathology, etiology, and work-up. J Am Acad Dermatol. 2011;65(3):473-91. doi: 10.1016/j.jaad.2010.11.061.

4. Birlea SA, Costin GE, Norris DA. New insights on therapy with vitamin $\mathrm{D}$ analogs targeting the intracellular pathways that control repigmentation in human vitiligo. Med Res Rev. 2009;29(3):514-46. doi: 10.1002/med.20146.

5. Taieb A, Alomar A, Böhm M, Dell'Anna ML, De Pase A, Eleftheriadou V, et al. Guidelines for the management of vitiligo: the European Dermatology Forum consensus. Br J Dermatol. 2013;168(1):5-19. doi: 10.1111/j.1365-2133.2012.11197.x.

6. Yazdani Abyaneh M, Griffith RD, Falto-Aizpurua L, Nouri K. Narrowband ultraviolet B phototherapy in combination with other therapies for vitiligo: mechanisms and efficacies. J Eur Acad Dermatol Venereol. 2014;28(12):1610-22. doi: 10.1111/ jdv.12619.

7. Xu H, Elmets CA. UVB immunosuppression: vitamin D or not vitamin D? That is the question. J Invest Dermatol. 2012;132(12):2676-8. doi: 10.1038/ jid.2012.327.

8. Silverberg JI, Silverberg AI, Malka E, Silverberg NB. A pilot study assessing the role of 25 hydroxy vitamin D levels in patients with vitiligo vulgaris. 
J Am Acad Dermatol. 2010;62(6):937-41. doi: 10.1016/j.jaad.2009.11.024.

9. Silva de Castro CC, do Nascimento LM, Olandoski M, Mira MT. A pattern of association between clinical form of vitiligo and disease-related variables in a Brazilian population. J Dermatol Sci. 2012;65(1):63-7. doi: 10.1016/j.jdermsci.2011.09.011.

10. Mchepange UO, Gao XH, Liu YY, Liu YB, Ma L, Zhang L, et al. Vitiligo in North-Eastern China: An association between mucosal and acrofacial lesions. Acta Derm Venereol. 2010;90(2):136-40.

11. Ohguchi R, Kato H, Furuhashi T, Nakamura M, Nishida E, Watanabe S, et al. Risk factors and treatment responses in patients with vitiligo in Japan--A retrospective large-scale study. Kaohsiung J Med Sci. 2015;31(5):260-4. doi: 10.1016/j. kjms.2015.02.003.

12. Casas MY, Torres PA. Enfermedad ocular y auditiva asociada al vitiligo. Rev Asoc Colomb Dermatol. 2017;24(1):29-37.

13. Kawakami T, Hashimoto T. Disease severity indexes and treatment evaluation criteria in vitiligo. Dermatol Res Pract. 2011;2011:750342. doi: 10.1155/2011/750342.

14. van Geel N, Lommerts J, Bekkenk M, Wolkerstorfer A, Prinsen CAC, Eleftheriadou V, et al. Development and validation of the Vitiligo Extent Score (VES): an International Collaborative Initiative. J Invest Dermatol. 2016;136(5):978-84. doi: 10.1016/j. jid.2015.12.040.

15. Kohli I, Veenstra J, Hamzavi I. Vitiligo assessment methods - Vitiligo Area Scoring Index and Vitiligo European Task Force assessment. Br J Dermatol. 2015;172(2):318-9. doi: 10.1111/bjd.13531.

16. van Geel N, Lommerts JE, Bekkenk MW, Prinsen CA, Eleftheriadou V, Taieb A, et al. Development and validation of a patient-reported outcome measure in vitiligo: The Self Assessment Vitiligo Extent Score (SA-VES). J Am Acad Dermatol. 2017;76(3):464-71. doi: 10.1016/j.jaad.2016.09.034.

17. Lotti T, Buggiani G, Troiano M, Assad GB, Delescluse J, De Giorgi V, et al. Targeted and combination treatments for vitiligo comparative evaluation of different current modalities in 458 subjects. Dermatol Ther. 2008;21 Suppl 1:S20-6. doi: 10.1111/j.1529-8019.2008.00198.x.

18. Khurrum H, AlGhamdi KM. The relationship between the serum level of vitamin D and vitiligo: A controlled study on 300 subjects. J Cutan Med Surg. 2016;20(2):139-45. doi: 10.1177/1203475415610071.

19. Saleh HMA, Abdel Fattah NSA, Hamza H-TMM. Evaluation of serum 25-hydroxyvitamin D levels in vitiligo patients with and without autoimmune diseases: Serum 25-hydroxyvitamin D levels in vitiligo. Photodermatol Photoimmunol Photomed. 2013;29(1):34-40. doi: 10.1111/phpp.12016.

20. Dell'Anna ML, Mastrofrancesco A, Sala R, Venturini $\mathrm{M}$, Ottaviani $\mathrm{M}$, Vidolin $\mathrm{AP}$, et al. Antioxidants and narrow band-UVB in the treatment of vitiligo: A double-blind placebo controlled trial. Clin Exp Dermatol. 2007;32(6):631-6.

21. Takci Z, Tekin Ö, Ertuğru DT, Karadağ AS, Akin KO. A case-control study: evaluation of vitamin D metabolism in patients with vitiligo. Turk J Med Sci. 2015;45(4):837-41.

22. Kechichian E, Ezzedine K. Vitamin D and the skin: An update for dermatologists. Am J Clin Dermatol. 2018;19(2):223-35. doi: 10.1007/s40257-017-0323-8.

23. Lips P. Worldwide status of vitamin D nutrition. J Steroid Biochem Mol Biol. 2010;121(1-2):297-300. doi: 10.1016/j.jsbmb.2010.02.021.

24. Mostafa WZ, Hegazy RA. Vitamin D and the skin: Focus on a complex relationship: A review. J Adv Res. 2015;6(6):793-804. doi: 10.1016/j. jare.2014.01.011.

25. Harinarayan CV, Holick MF, Prasad UV, Vani PS, Himabindu G. Vitamin D status and sun exposure in India. Dermatoendocrinol. 2013;5(1):130-41. doi: 10.4161/derm.23873.

26. Pludowski P, Grant WB, Bhattoa HP, Bayer M, Povoroznyuk $\mathrm{V}$, Rudenka E, et al. Vitamin D status in Central Europe. Int J Endocrinol. 2014;2014:589587. doi: 10.1155/2014/589587.

27. Vanchinathan V, Lim HW. A dermatologist's perspective on vitamin D. Mayo Clin Proc. 2012;87(4):3728o. doi: 10.1016/j.mayocp.2011.12.010.

28. Wadwa B, Relhan V, Goel K, Kochhar A, Garg V. Vitamin D and skin diseases: A review. Indian J Dermatol Venereol Leprol. 2015;81(4):344-55. doi: 10.4103/0378-6323.159928.

29. Birlea SA, Costin GE, Norris DA. Cellular and molecular mechanisms involved in the action of vitamin $\mathrm{D}$ analogs targeting vitiligo depigmentation. Curr Drug Targets. 2008;9(4):345-59.

30. Huang CL, Nordlund JJ, Boissy R. Vitiligo: a manifestation of apoptosis? Am J Clin Dermatol. 2002;3(5):301-8.

31. Ben-Shoshan M. Vitamin D deficiency/insufficiency and challenges in developing global vitamin D fortification and supplementation policy in adults. Int J Vitam Nutr Res. 2012;82(4):237-59. doi: 10.1024/0300-9831/a0oo117.

32. Kulling PM, Olson KC, Olson TL, Feith DJ, Loughran TP Jr. Vitamin D in hematological disorders and 
malignancies. Eur J Haematol. 2017 Mar;98(3):187197. doi: 10.1111/ejh.12818. Epub 2016 Nov 21.

33. UV exposure guidance: a balanced approach between health risks and health benefits of UV and vitamin D. Prog Biophys Mol Biol. 2006;92(1):1184.

34. Díaz ME, Llinas A. Niveles de vitamina D y prevalencia de déficit de vitamina $D$ ” en mujeres postmenopáusicas mayores de 50 años en Bogotá [Internet]. Universidad del Rosario - Universidad CES; 2014 [cited 2017 Feb 26]. Recuperado de: http://repository.urosario.edu.co/ bitstream/handle/10336/9037/80871284-2014. pdf? sequence $=5$ \&isAllowed $=\mathrm{y}$.

35. Van der Meer IM, Middelkoop BJC, Boeke AJP, Lips P. Prevalence of vitamin D deficiency among Turkish, Moroccan, Indian and sub-Sahara African populations in Europe and their countries of origin: an overview. Osteoporos Int. 2011;22(4):1009-21. doi: 10.1007/s00198-010-1279-1.

36. Reichrath J, Zouboulis CC, Vogt T, Holick MF. Targeting the vitamin D endocrine system (VDES) for the management of inflammatory and malignant skin diseases: An historical view and outlook. Rev Endocr Metab Disord. 2016;17(3):405-17.

37. Piotrowska A, Wierzbicka J, Żmijewski MA. Vitamin D in the skin physiology and pathology. Acta Biochim Pol. 2016;63(1):17-29. doi: 10.18388/ abp.2015_1104.

38. Upala S, Sanguankeo A. Low 25-hydroxyvitamin D levels are associated with vitiligo: A systematic review and meta-analysis. Photodermatol Photoimmunol Photomed. 2016;32(4):181-90. doi: 10.1111/ phpp.12241.

39. Xu X, Fu WW, Wu WY. Serum 25-hydroxyvitamin D deficiency in Chinese patients with vitiligo: A case-control study. PLoS One. 2012;7(12):e52778. doi: 10.1371/journal.pone.0052778.

40. Doss R, El-Rifaie AA, Gohary Y, Rashed L. Vitamin $\mathrm{D}$ receptor expression in vitiligo. Indian $\mathrm{J}$ Dermatol. 2015;60(6):544-8. doi: 10.4103/00195154.169123.

41. Aksu Cerman A, Sarikaya Solak S, Kivanc Altunay I. Vitamin D deficiency in alopecia areata. Br J Dermatol. 2014;170(6):1299-304. doi: 10.1111/ bjd.12980.

42. Karagüzel G, Sakarya NP, Bahadır S, Yaman S, Ökten A. Vitamin D status and the effects of oral vitamin D treatment in children with vitiligo: A prospective study. Clin Nutr ESPEN. 2016;15:28-31. doi: 10.1016/j.clnesp.2016.05.006.
43. Sehrawat M, Arora TC, Chauhan A, Kar HK, Poonia A, Jairath V. Correlation of vitamin D levels with pigmentation in vitiligo patients treated with NBUVB therapy. ISRN Dermatol. 2014;2014:493213. doi: $10.1155 / 2014 / 493213$.

44. Finamor DC, Sinigaglia-Coimbra R, Neves LC, Gutiérrez M, Silva JJ, Torres LD, et al. A pilot study assessing the effect of prolonged administration of high daily doses of vitamin D on the clinical course of vitiligo and psoriasis. Dermatoendocrinol. 2013;5(1):222-34. doi: 10.4161/derm.24808.

45. Lehmann B, Querings K, Reichrath J. Vitamin D and skin: new aspects for dermatology. Exp Dermatol. 2004 Dec;13(s4):11-5.

46. Albenali LH, Danby S, Moustafa M, Brown K, Chittock J, Shackley F, et al. Vitamin D and antimicrobial peptide levels in patients with atopic dermatitis and atopic dermatitis complicated by eczema herpeticum: A pilot study. J Allergy Clin Immunol. 2016 Dec;138(6):1715-1719.e4.

47. Hata TR, Audish D, Kotol P, Coda A, Kabigting F, Miller J, et al. A randomized controlled doubleblind investigation of the effects of vitamin D dietary supplementation in subjects with atopic dermatitis. J Eur Acad Dermatol Venereol. 2014 Jun;28(6):781-9.

48. Peroni DG, Piacentini GL, Cametti E, Chinellato I, Boner AL. Correlation between serum 25-hydroxyvitamin D levels and severity of atopic dermatitis in children: Atopic dermatitis and vitamin D. Br J Dermatol. 2011 May;164(5):1078-82.

49. Javanbakht MH, Keshavarz SA, Djalali M, Siassi F, Eshraghian MR, Firooz A, et al. Randomized controlled trial using vitamins E and D supplementation in atopic dermatitis. J Dermatol Treat. 2011 Jun;22(3):144-50.

50. Kılıç S, Sılan F, Hız M, Işık S, Ögretmen Z, Özdemir ö. Vitamin D Receptor Gene BSMI, FOKI, APAI, and TAQI Polymorphisms and the Risk of Atopic Dermatitis. J Investig Allergol Clin Immunol. 2016 Apr 1;26(2):106-10.

51. Heine G, Hoefer N, Franke A, Nöthling U, Schumann RR, Hamann L, et al. Association of vitamin $D$ receptor gene polymorphisms with severe atopic dermatitis in adults: VDR SNPs in atopic dermatitis. Br J Dermatol. 2013 Apr;168(4):855-8.

52. Camargo CA, Ganmaa D, Sidbury R, Erdenedelger K, Radnaakhand N, Khandsuren B. Randomized trial of vitamin D supplementation for winter-related atopic dermatitis in children. J Allergy Clin Immunol. 2014 Oct;134(4):831-835.e1. 
53. Schlager JG, Rosumeck S, Werner RN, Jacobs A, Schmitt J, Schlager C, et al. Topical treatments for scalp psoriasis: summary of a Cochrane Systematic Review. Br J Dermatol. 2017 Mar;176(3):60414.

54. Soleymani T, Hung T, Soung J. The role of vitamin D in psoriasis: a review. Int J Dermatol. 2015 Apr;54(4):383-92.

55. Bergler-Czop B, Brzezińska-Wcisło L. Serum vitamin D level - the effect on the clinical course of psoriasis. Adv Dermatol Allergol. 2016;6:445-9.

56. Giuggioli D, Colaci M, Cassone G, Fallahi P, Lumetti F, Spinella A, et al. Serum 25-OH vitamin D levels in systemic sclerosis: analysis of 140 patients and review of the literature. Clin Rheumatol. 2017 Mar;36(3):583-90.

57. Malloy PJ, Feldman D. The role of vitamin D receptor mutations in the development of alopecia. Mol Cell Endocrinol. 2011 Dec;347(1-2):90-6.

58. Ghafoor R, Anwar MI. Vitamin D Deficiency in Alopecia Areata. J Coll Physicians Surg--Pak JCPSP. 2017 Apr;27(4):200-2.

59. Wu PW, Rhew EY, Dyer AR, Dunlop DD, Langman $\mathrm{CB}$, Price $\mathrm{H}$, et al. 25-hydroxyvitamin D and cardiovascular risk factors in women with systemic lupus erythematosus. Arthritis Rheum. 2009 Oct 15;61(10):1387-95.

6o. Amital H, Szekanecz Z, Szucs G, Danko K, Nagy E, Csepany T, et al. Serum concentrations of $25-\mathrm{OH}$ vitamin D in patients with systemic lupus erythematosus (SLE) are inversely related to disease activity: is it time to routinely supplement patients with SLE with vitamin D? Ann Rheum Dis. 2010 Jun 1;69(6):1155-7.

61. Mok C, Birmingham D, Ho L, Hebert L, Song H, Rovin B. Vitamin D deficiency as marker for disease activity and damage in systemic lupus erythematosus: a comparison with anti-dsDNA and anti-C1q. Lupus. 2012 Jan;21(1):36-42.

62. Gruber-Wackernagel A, Obermayer-Pietsch B, Byrne SN, Wolf P. Patients with polymorphic light eruption have decreased serum levels of 25-hydroxyvitamin-D 3 that increase upon $311 \mathrm{~nm}$ UVB photohardening. Photochem Photobiol Sci. 2012;11(12):1831-6.

63. Muehleisen B, Bikle DD, Aguilera C, Burton DW, Sen GL, Deftos LJ, et al. PTH/PTHrP and Vitamin D Control Antimicrobial Peptide Expression and Susceptibility to Bacterial Skin Infection. Sci Transl Med. 2012 May 23;4(135):135ra66-135ra66.
64. Martineau AR, Newton SM, Wilkinson KA, Kampmann B, Hall BM, Nawroly N, et al. Neutrophil-mediated innate immune resistance to mycobacteria. J Clin Invest. 2007 Jul 2;117(7):1988-94.

65. Carless MA, Kraska T, Lintell N, Neale RE, Green AC, Griffiths LR. Polymorphisms of the VDR gene are associated with presence of solar keratoses on the skin. Br J Dermatol. 2008 Oct;159(4):804-10.

66. Bijlsma MF, Spek CA, Zivkovic D, van de Water S, Rezaee F, Peppelenbosch MP. Repression of Smoothened by Patched-Dependent (Pro-)Vitamin D3 Secretion. Scott M, editor. PLoS Biol. 2006 Jul 18;4(8):e232.

67. For the Osteoporotic Fractures in Men (MrOS) Study Group, Tang JY, Parimi N, Wu A, John Boscardin W, Shikany JM, et al. Inverse association between serum $25(\mathrm{OH})$ vitamin D levels and nonmelanoma skin cancer in elderly men. Cancer Causes Control. 2010 Mar;21(3):387-91.

68. Rasheed H, Hegazy RA, Gawdat HI, Mehaney DA, Kamel MM, Fawzy MM, et al. Serum Vitamin D and Vitamin D Receptor Gene Polymorphism in Mycosis Fungoides Patients: A Case Control Study. Zmijewski M, editor. PLOS ONE. 2016 Jun 23;11(6):e0158014.

69. Orlow I, Roy P, Reiner AS, Yoo S, Patel H, Paine $\mathrm{S}$, et al. Vitamin D receptor polymorphisms in patients with cutaneous melanoma. Int J Cancer. 2012 Jan 15;130(2):405-18.

70. Newton-Bishop JA, Beswick S, Randerson-Moor J, Chang Y-M, Affleck P, Elliott F, et al. Serum 25-Hydroxyvitamin $D_{3}$ Levels Are Associated with Breslow Thickness at Presentation and Survival From Melanoma. J Clin Oncol. 2009 Nov 10;27(32):5439-44.

71. Field S, Davies J, Bishop DT, Newton-Bishop JA. Vitamin D and melanoma. Dermatoendocrinol. 2013 Jan;5(1):121-9.

72. Wrzosek M, Łukaszkiewicz J, Wrzosek M, Jakubczyk A, Matsumoto H, Piątkiewicz P, et al. Vitamin $\mathrm{D}$ and the central nervous system. Pharmacol Rep. 2013;65(2):271-8. 